\title{
Currículo e gestão: propondo uma parceria
}

\author{
Antonio Flavio Barbosa Moreira*
}

\section{Resumo}

Muitas escolas têm deixado de ensinar aos alunos o que pode vir a ser necessário em um futuro incerto. Para oferecer os conhecimentos, habilidades e valores indispensáveis para viver no mundo de hoje, a escola deve ser repensada e renovada. A bem-sucedida experiência finlandesa em educação pode ser útil para nos incentivar a sonhar com uma escola de qualidade, a envidar esforços para construi-la, a lidar criticamente com as experiências estrangeiras, a respeitar e valorizar o professor e a criar um clima livre de ameaças nas escolas e nas salas de aula. Na negociação dessa qualidade, o currículo pode ser elemento central. Há que se discuti-lo, levando em conta, principalmente, a cultura em que se insere e o conhecimento escolar. Nesse processo, é essencial a cooperação na escola, com a promoção de diálogos entre escola e secretaria de educação e entre os diferentes profissionais que atuam na instituição escolar.

Palavras-chave: Escola. Currículo. Gestão. Cultura. Conhecimento escolar.

Devia, era logo de manhã, passar um sonho pelo rosto. É isso que impede o tempo e atrasa a ruga.

MIA COUTO

\section{Introdução}

Nos dias de hoje, muitas escolas, em escala mundial, têm deixado de oferecer aos alunos as oportunidades essenciais para aprender o que possa ser necessário no incerto futuro que os espera. A demanda por qualidade e eficiência em educação faz-se ouvir em várias partes do globo, particularmente em um momento no qual uma cruel crise econômica tem assolado inúmeros países e provocado uma situação de desemprego que penaliza muitos cidadãos em idade produtiva e em condições de contribuir para o bem-estar geral. Em situação tão difícil e complexa, há que se promover uma educação que garanta a apropriação de conhecimentos, habilidades e visões de mundo que se mostrem indispensáveis para poder viver, conviver, lutar e sobreviver no mundo contemporâneo. Para isso, porém, há que se valorizar, repensar e renovar a escola, ampliando-a no sentido de reconhecer e de bem aproveitar

* Dr. em Educação, University of London. Professor da Universidde Católica de Petrópolis (UCP) e da Universidade Federal do Rio de Janeiro (UFRJ). E-mail: afmcju@gmail.com 
outros espaços e outras configurações em que se adquirem informações e saberes e se constroem as identidades de nossos estudantes.

Nesse processo de renovação, há que se favorecer o diálogo entre diferentes conhecimentos e linguagens, há que se buscar a articulação entre igualdade e diferença (na perspectiva de uma educação intercultural), há que se favorecer uma abordagem de cidadania que a conceba como prática social cotidiana presente nos diferentes âmbitos de nossa vida. 0 que se está propondo, em última análise, é 0 que Candau (2000a) denomina de reinvenção da escola.

Reinventar a escola demanda uma atitude crítica e de insatisfação com a escola atual, bem como a conviç̧ão de que outra escola, qualitativamente distinta da de hoje, é possivel. Não se trata de problemas de eficácia, mas de problemas de legitimidade na escola. Faz-se necessária uma metodologia de mudança que se fundamente na criatividade das escolas, de modo que, ao mudarem, elas se transformem em comunidades de aprendizagem. Nessa perspectiva, as estratégias de mudança são decididas e construidas com os professores, garantindo-se sua autonomia profissional e seu controle sobre o processo de trabalho. (CANÁRIO, 2006).

Em diversos países, inclusive no Brasil, nos quais essa reinvenção ainda não ocorreu como seria de desejar, a escola pública é vista como em crise e o sistema de ensino continua a mostrar-se diferenciado, conforme a escola e o alunado. Em muitos casos, a suposta solução para os problemas tem-se caracterizado pelo aumento de regulação de professores e escolas, com o estabelecimento de padrões nacionais, currículos nacionais e exames nacionais. Nas reformas propostas, duas dinâmicas têm sido recorrentes: os mercados livres e a vigilância ampliada. Os testes e os indicadores de desempenho têm contribuído para possibilitar a classificação das escolas, a avaliação dos docentes e dos alunos, a definição de critérios que recompensem ou não o professor. Em todo esse contexto, caminha-se a passos largos em direção a um maior controle e a uma maior mercantilização da educação.

Inúmeros estudos já demonstraram o quanto essas reformas têm, de fato, privilegiado os que detêm o capital cultural dominantemente valorizado e transmitido nos sistemas escolares. Entretanto, para que os desfavorecidos não sejam ainda mais prejudicados, há que se contrapor, ao conjunto de inciativas que caracterizam a "guinada para a direita" na educação, um significativo esforço por elaborar e difundir amplamente politicas e práticas alternativas críticas, progressistas, defensáveis, articuladas e consistentes no que se refere a gestão, currículo, ensino e avaliação. Ou seja, urgem respostas coletivas e construtivas que desafiem as políticas educacionais pautadas na chamada restauração conservadora na educação. (APPLE, 2002). 
Uma outra escola é apresentada em livro há pouco publicado (SAHLBERG, 2011), que aborda a educação na Finlândia e procura discutir a situação de excelência que hoje parece marcá-la. Indicadores internacionais têm evidenciado que, naquele pais, se encontram cidadãos muito bem educados, se oferecem oportunidades educacionais igualitariamente e se faz um adequado e efetivo uso dos recursos necessários ao desenvolvimento do processo educacional.

Inicialmente, há que se reconhecer a impossibilidade de se indicar um único fator que responda pelo sucesso ou fracasso de um sistema educacional, cujo funcionamento depende de uma rede de elementos sociais, culturais, políticos, econômicos e educacionais, que se articulam diferentemente em diferentes situações. Sahlberg (2011), ao examinar o sistema escolar na Finlândia, menciona três aspectos que precisam ser considerados na análise de seu bom desempenho. Passemos a eles.

Em primeiro lugar, uma inspiradora visão do que deve ser a educação pública é dominante no pais. Os finlandeses têm-se mostrado fortemente comprometidos com a construção de uma escola básica para todas as crianças, publicamente financiada e localmente governada. Tal compromisso tem resistido a inúmeras mudanças no governo e no Ministério da Educação e, em função de sua persistência, está sendo denominado de sonho finlandês.

Em segundo lugar, importa acentuar como o pais tem tratado tanto o auxílio externo quanto a sua própria tradição educacional nas reformas que tem promovido. A despeito das influências e das transferências ocorridas ao longo do tempo, a Finlândia terminou por chegar a uma forma própria de criar o sistema educacional que hoje existe. Essa modalidade finlandesa de agir é claramente diferente do movimento das reformas educacionais de viés neoliberal que têm sido implementadas em inúmeros países durante as duas últimas décadas. A modalidade finlandesa de mudança preserva o melhor de sua tradição e de sua prática pedagógica, combinando-as com inovações formuladas em outros lugares. 0 cultivo da confiança, o incremento da autonomia e a valorização da diversidade constituem exemplos de ideias norteadoras de transformações nas escolas finlandesas. A despeito dos modelos importados de inúmeros países (como Estados Unidos, Inglaterra, Austrália, Canadá e outros), o sonho finlandês é vivido como algo de propriedade dos cidadãos, ao invés de algo tomado de empréstimo.

Em terceiro lugar, há um sistemático e respeitoso desenvolvimento de adequadas condições de trabalho para professores e gestores nas escolas finlandesas. Existe a preocupação em recrutar jovens promissores para o magistério. Mas, admite-se, que não bastam bons cursos de formação nem bons salários. A diferença, na Finlândia, é que os professores podem exercer sua capacidade profissional e empregar seu 
poder de julgamento ampla e livremente nas escolas. Cabem aos docentes, então, o controle do currículo, a avaliação do aluno, o aprimoramento da escola e o envolvimento com a comunidade.

Sahlberg reconhece, acertadamente, que a experiência finlandesa não pode ser transferida para outros paises. Contudo, insiste na possibilidade, em qualquer pais, de se acreditar na competência do professor, de se adotar um clima livre de ameaças nas salas de aula e de se buscar promover um ambiente de confiança nas escolas.

Recorro, então, à experiência finlandesa como contraposição às reformas neoliberais que primam pela intensificação do controle e da mercantilização na educação. Utilizo-a, também, para estimular a discussão das relações entre currículo e gestão. Nas minhas reflexões, pretendo defender o argumento de que decisões curriculares efetivas e democráticas nas escolas vêm a ser facilitadas não pelo aumento de controle dos docentes e dos alunos, mas pela promoção de um clima de confiança e de apoio nas salas de aula.

Nesse processo, uma abordagem democrática e teoricamente fundamentada do currículo se faz indispensável. Insisto, então, no ponto de vista de que o desenvolvimento de uma qualidade negociada via currículo precisa pautar-se no diálogo e na cooperação entre diferentes grupos Tal qualidade deve derivar da transação, da colaboração, da reflexão e da análise crítica de documentos oficiais, bem como de um debate constante entre os diferentes sujeitos envolvidos no processo. Desse debate, devem participar os que respondem pela gestão, tanto em nível sistêmico quanto escolar, assim como os demais profissionais que, nas escolas e nas salas de aula, desempenham papel central no planejamento e na construção do currículo.

Organizo o texto da seguinte forma. Apresento, inicialmente, o que tenho chamado de qualidade negociada via currículo. Destaco, a seguir, princípios que possam nortear iniciativas voltadas para o desdobramento de um clima de negociação, apoio e confiança nas escolas. Defendo, nesse momento, a valorização da escola e do ensino. Em terceiro lugar, ressalto a importância do conhecimento escolar e da cultura mais ampla no processo curricular. Por fim, apresento considerações finais em que articulo os argumentos apresentados ao longo do texto e acentuo 0 valor de um esforço colaborativo e democrático nas decisões curriculares, para que se incremente uma atmosfera livre de ameaças no espaço escolar.

\section{Qualidade negociada via currículo}

Considero por demais restritas as visões de qualidade em educação que priorizam desempenho satisfatório em exames nacionais; domínio de conhecimentos, habilidades e competências que se estabeleçam antecipadamente; emprego de tecnologias avançadas; supervalorização da competividade e da produtividade; novos métodos de 
gerenciar sistemas e instituições educacionais; procedimentos integrados e flexíveis no trabalho pedagógico. Como afirmam Moreira e Kramer (2007),

alguns desses elementos podem integrar uma concepção crítica. Todavia, não se ultrapassa o nivel instrumental quando a noção de qualidade se funda apenas em pressupostos técnicos e se distancia dos juizos de valor, do compromisso com a justiça social, bem como das ações e dos interesses dos sujeitos que concretamente a definem e adotam. (p. 1044).

Posiciono-me, assim, na contramão das tentativas de congelar o sentido da palavra qualidade, que a associam, fundamentalmente, aos resultados em avaliações nacionais e internacionais e às perspectivas neoliberais que têm norteado recentes reformas educacionais. Argumento a favor de outra ótica, com base na qual se entenda o sentido de qualidade em educação, dominantemente, como uma perspectiva utópica, como um processo de formulação de alternativas desenvolvido por sujeitos que interagem, articulando dimensões intelectuais, sociais, culturais e políticas. Sustento que a abordagem da professora italiana Anna Bondioli (2004) corresponde a esse ângulo de análise. A autora sugere uma qualidade negociada, definida com base no diálogo e nas contribuições de diversos grupos de trabalho. Essa qualidade caracteriza-se por sua natureza: (a) transacional; (b) participativa e polifônica; (c) autorreflexiva; (d) contextual; (e) processual; (f) transformadora; e (g) formadora.

Essa visão de qualidade pode incentivar um processo contínuo de interação e de inovação, centrado na criatividade dos professores e das escolas e na sua capacidade para, constante e coletivamente, definir, avaliar e retificar o processo pedagógico. Qualidade resulta, então, de transação, de cooperação, de reflexão, de um debate constante entre os diversos atores e grupos sociais interessados nos distintos aspectos e nas diferentes dimensões do fenômeno educativo escolar. Nesse enfoque, a qualidade pode ser favorecida pela parceria entre escola e governo local, em função de um processo que, me inspirando em Luiz Carlos de Freitas (2007), denomino de qualidade negociada via currículo. Trata-se, em última análise, de aproveitar os subsídios, o apoio e os recursos oriundos do governo municipal, articulando-os aos esforços da escola na elaboração e na materialização de seu projeto político-pedagógico e de seu currículo. Em vez de determinações verticais e autoritárias, estou sugerindo a parceria entre a escola e o governo local, para que ela cumpra a sua função "de ensinar a todos e $a$ cada um" (Freitas, 2007, p. 980, itálicos no original).

Quero argumentar que essa perspectiva associa-se à valorização da escola, à busca de soluções pautadas na realidade local e ao desenvolvimento de um clima sem ameaças nas escolas, tal como ocorre na Finlândia. Em cena, apresenta-se uma nova modalidade de ação por parte das secretarias locais, que passam a substituir iniciativas de regulação por uma postura de cooperação e de solidariedade com as escolas. 
Nessa proposta de colaboração, destacam-se, vale reiterar, o respeito à escola e a crença em sua capacidade de debater, analisar e decidir. A essa escola dirijo, então, minha atenção.

\section{A importância da escola}

Os olhares de muitos estudiosos do currículo já se têm voltado para outras instâncias e outros processos que também constituem territórios educativos, ampliando a própria ideia de curriculo. Embora reconhecendo que um dos desafios do atual momento seja exatamente identificar, favorecer e expandir distintos espaços de construção e de reconstrução do conhecimento, para neles pensar, de forma renovada, a didática e o currículo (Candau, 2000b), opto por privilegiar a escola e por acentuar a sua capacidade de realização, resistência e transgressão.

Faço-o ciente de que valorizar a escola não significa abordá-la inocente ou romanticamente. A escola e o currículo estão implicados no processo de reprodução de desigualdades sociais e de relações de poder assimétricas. A função reprodutora do processo de escolarização foi acentuada por Apple (1989), para quem as escolas, na sociedade capitalista, contribuem para os processos de acumulação, legitimação e produção. Primeiramente, as escolas auxiliam no processo de acumulação ao selecionarem, classificarem e prepararem os alunos com base em seus distintos "talentos", reproduzindo, assim, uma força de trabalho hierarquicamente organizada. Em segundo lugar, as escolas participam de uma complexa estrutura por meio da qual os grupos sociais adquirem legitimidade e por meio da qual as visões de mundo e os significados são recriados, mantidos e continuamente reelaborados. Finalmente, escolas e universidades contribuem para a produção do conhecimento técnico-administrativo necessário à expansão da indústria e do mercado.

Mas os processos de acumulação, legitimação e produção representam pressões sobre as escolas, não conclusões garantidas, pois se desenvolvem em meio a contradições, conflitos e resistências. Por esse motivo, o currículo escolar será sempre o resultado de disputas, alianças e negociações entre grupos econômica e culturalmente poderosos (que procuram defender seus interesses) e as classes populares (que buscam tornar o currículo mais adequado às suas tradições políticas e culturais).

Compreender as vinculações da escola e do currículo com a economia e a produção continua a apresentar relevância. Porém, como na escola se produzem diversas competências, capacidades e habilidades, faz sentido considerá-la como frente privilegiada de luta de qualquer estratégia de intervenção cultural do processo de transformação social. Segundo Silva $(1996,1999)$ esse processo de transformação não deve sustentar-se em qualquer projeto distante, mas deve, sim, procurar afetar as relações de poder e de dominação presentes em nossa vida cotidiana. 
No que se refere à configuração de nossas identidades sociais, a escola tem sido vista como um dos mais importantes espaços institucionais na construção de quem somos. É um dos primeiros espaços em que a criança se situa, distante do convívio e da vigilância da familia. A criança tem, então, acesso a outros modos de ser e de agir diferentes dos que encontra no mundo familiar. Expõe-se às diferenças que nos conformam, o que contribui para desestabilizar as crenças e as condutas aceitas no âmbito da família (MOITA LOPES, 2002).

A escola pode, então, voltar-se para o movimento e a mudança, para a abertura e a dissidência, para a transgressão e a subversão (SILVA, 1996). Pode favorecer a formação de indivíduos não conformistas, questionadores, rebeldes, autônomos, capazes de criticar e de desafiar os valores dominantes e as identidades celebradas no mundo da família e na sociedade mais ampla. Pode constituir um território de lutas, buscas, relações, diálogos, confrontos, desafios e práticas que anunciem novos tempos (ALVES; GARCIA, 1999; CANDAU, 2000b). Pode, em síntese, fazer diferença. Daí a necessidade de valorizá-la e de, ao mesmo tempo, renová-la.

Partindo desses pontos de vista, ressaltei, em recente texto (MOREIRA, 2012), a importância da escola como: espaço de crítica cultural, espaço de pesquisa e espaço formativo para o trabalho. Primeiramente, argumentei que a escola precisa desenvolver no estudante a capacidade de critica cultural, de crítica do existente, de questionamento do que parece inscrito na natureza das coisas, com a intenção de mostrar que as coisas não são inevitáveis. Trata-se, em outras palavras, de tornar evidente que muito do que é visto como natural e aceito sem questionamento, assim o é por atender à manutenção de privilégios e vantagens de dados grupos sociais. Trata-se, então, de desfamiliarizar o que a rotina, personagem habitual da vida cotidiana, costuma consolidar. Trata-se de colocar em questão as certezas inabaláveis e os interesses estabelecidos.

Em segundo lugar, sugeri que se concebesse a escola como espaço de pesquisa, construção e reconstrução do conhecimento. Sustentei que o professor, ao participar do esforço por universalizar bens materiais e simbólicos necessários ao enfrentamento de problemas comuns, precisa cruzar a fronteira entre o acadêmico e o político, o que exige sair do confortável terreno acadêmico e entrar em contato com o mundo exterior (sindicatos, movimentos sociais e outros grupos). Precisa inventar o conhecimento engajado (BOURDIEU, 2001) - uma política de intervenção no mundo político que obedeça às regras e aos métodos do campo científico.

Esse conhecimento poderá incrementar tanto a crítica às políticas e decisões que os neoliberais nos apresentam como inevitáveis, quanto a formulação de alternativas ao que é tido como inquestionável. Tornar a escola um espaço de pesquisa requer um 
trabalho cooperativo com base no qual os docentes se constituam em pesquisadores dos conteúdos que ensinam, das práticas que organizam e coordenam ou, ainda, aprendam a centrar o próprio ensino na habilidade de pesquisar. Tornar a escola um espaço de pesquisa pode ser facilitado pelo apoio da secretaria local e depende, indiscutivelmente, da salutar parceria entre docentes e gestores. Tornar a escola um espaço de pesquisa pode contribuir para o aperfeiçoamento profissional dos professores; para que os estudantes desenvolvam a curiosidade, a criatividade, 0 interesse pela busca de novos saberes e informações, o rigor nessa busca, ou seja, o espírito de pesquisa. A meu ver, do desdobramento desse processo poderão delinearse incontestáveis motivos para a maior valorização dos professores no âmbito da sociedade e da cultura em que atuam.

0 espaço de pesquisa que proponho corresponde, também, a um espaço político (APPLE, 2002; BOURDIEU, 2001). Nele, é proveitosa a articulação de movimentos que se mobilizem contra a hegemonia, de tal modo que as lutas educacionais se associem às lutas em outras frentes, com a possivel emergência de novas lutas e o fortalecimento das que já existam nas próprias instituições educacionais. Nesse contexto, em que cooperação, negociação, participação, polifonia, respeito à diferença, bem como capacidade de ouvir o outro e de dialogar são inevitáveis, pode-se melhor atingir a qualidade negociada via currículo.

Em terceiro lugar, proponho que se conceba a escola como espaço formativo para o trabalho, já que o trabalho é uma das principais atividades humanas. 0 que estou sugerindo é tornar a escola um campo de preparação para futuras escolhas profissionais; um lugar de exercício da cidadania; um terreno de produção de bens, serviços e conhecimentos. Para isso, importa uma clara compreensão do processo histórico de produção científica e tecnológica, assim como de inovação. Importa uma análise cuidadosa e criteriosa do processo de trabalho no mundo contemporâneo. A intenção é facilitar a aquisição de conhecimentos escolares que constituam instrumentos adequados à compreensão e à transformação da natureza e das situações de vida, bem como ao aprofundamento das potencialidades humanas, Em última análise, estou argumentando a favor do preparo do estudante para refletir e agir em relação à natureza, ao contexto e à organização social.

Ciente de que a escola não se reduz ao ensino e de que não se aprende apenas na escola, sustento que a ela cabe, como tarefa básica, organizar e promover o ensino, desenvolvendo a aprendizagem, a construção e a reconstrução de conhecimentos, habilidades e visões de mundo, assim como promover a formação de cidadãos autônomos e responsáveis e contribuir para a construção de identidades que se coloquem na contramão dos modelos hegemônicos. Valorizar a escola implica, assim, valorizar o ensino, o currículo, o conhecimento escolar e as identidades. 
Com Apple (2010), considero que as decisões curriculares envolvem necessariamente professores, alunos, conhecimentos, salas de aula, assim como experiências e ambientes de aprendizagem. Ou seja, não há como negligenciarse a preocupação com o ensino, com o currículo, com a forma e o conteúdo do conhecimento escolar, com os sujeitos implicados no processo 0 esforço por compreender esses elementos, assim como suas relações e os propósitos que se pretende que cumpram devem estar na linha de frente de nossa atuação como professores e pesquisadores. Lamentavelmente, porém, como argumentou o pesquisador norte-americano, muito do que se encontra no chamado campo do currículo distanciou-se, lastimavelmente, dessa perspectiva.

\section{Currículo: conhecimento escolar e identidade}

Partindo do ponto de vista de que nos processos de negociação as decisões precisam ser teoricamente fundamentadas, abordo o campo do currículo, a fim de destacar dois elementos necessariamente pressentes nas teorizações que se formulam. Como tenho argumentado, as decisões curriculares precisam pautar-se nas contribuições das análises nacionais e internacionais que têm enfocado o conhecimento escolar, assim como os estudos que consideram a cultura mais ampla, discutindo fenômenos como globalização, diferença, identidade, multiculturalismo, pluralidade cultural, hibridização etc, claramente identificáveis nas sociedades de hoje. A abordagem apenas do local parece mostrar-se insuficiente para se conferir uma perspectiva mais abrangente ao processo curricular. Essa afirmativa se justifica, já que, nas escolas, o currículo funciona, tanto política quanto praticamente, segundo parâmetros de classe social, de raça, de gênero, de identidade e de "aldeia global".

0 que estou sustentando é que o processo curricular precisa pautar-se por análises do conhecimento escolar, assim como da diversidade cultural e da identidade. Defendo a atualidade e a articulação dessas temáticas nos currículos que se pretendam efetivos, democráticos, inovadores e inclusivos. Essas temáticas precisam ser objeto das discussões empenhadas na promoção da qualidade via currículo e na valorização dos professores.

A inclusão, nas reflexões e nas decisões referentes a currículo, de fenômenos culturais contemporâneos, secundarizados em muitas análises de questões curriculares pode justificar-se, inicialmente, pela argumentação de Stuart Hall (1997), que ressalta a centralidade da cultura nos fenômenos sociais, bem como nos estudos que sobre eles se formulam. Não faz sentido ver a cultura como mero reflexo de uma estrutura econômica: poucos aceitam a visão marxista ortodoxa que distinguia a base da superestrutura ideológica. A cultura é entendida, então, como representando um processo social constitutivo, que cria modos de vida distintos e específicos. (WILLIAMS, 1985). 
Esse papel constitutivo da cultura reflete-se em praticamente todos os aspectos do processo social. A conseqüência é o deslocamento da ênfase nos fenômenos socioeconômicos para os fenômenos culturais, o que contribui para o especial relevo assumido pela globalização cultural (SOUSA SANTOS, 2002). Nessa perspectiva, os "objetos" econômicos e políticos são vistos imersos na cultura e sendo por ela condicionados. Assim, sistemas econômicos particulares e formas de estado dependem de significados, interpretações, narrativas, valores, atitudes, identidades e com eles se articulam estreitamente. (FAIRCLOUGH, 2008).

Lipovetsky e Serroy (2010) reiteram a importância da cultura, que se impôs como um mundo econômico de pleno direito. Trata-se de um mundo sem fronteiras dos capitais e das multinacionais, do ciberespaço e do consumismo. Para os autores, a chamada cultura-mundo remete para a realidade planetária hipermoderna, em que a economia do mundo se organiza segundo um modelo único de normas, de valores e de objetivos.

Cultura-mundo significa fim da heterogeneidade tradicional da esfera cultural e universalização da cultura mercantil, que se apodera das esferas da vida social, dos modos de existência e da quase totalidade das atividades humanas. Com a culturamundo, alastra por todo o globo a cultura da tecnociência, dos mercados, dos media, do consumo e do indivíduo e com ela toda uma série de novos problemas, não só de âmbito global (ecologia, imigrações, crise econômica, miséria do terceiro mundo, terrorismo etc.), mas também existenciais (...) é o mundo que se transforma em cultura e a cultura em mundo: é uma cultura-mundo (LIPOVETSKY; SERROY, 2010, p. 13-14).

Mas os autores acentuam: as forças de unificação global progridem tanto quanto as da diversificação social, mercantil e individual. A cultura-mundo não implica uma cultura mundial una, nem unificada. Intensificam-se as hibridações do global e do local, a diversidade dos valores, as reivindicações particularistas, o que os autores denominam de "guerra dos deuses". 0 mundo tecnomercantil ajuda a reconfigurar as questões culturais, sob a forma da problemática das identidades coletivas, das raizes, do patrimônio, das identidades coletivas, das línguas nacionais, do religioso e do sentido. Quanto mais o mundo se globaliza, mais particularismos culturais buscam afirmar-se. Uniformização globalitária e fragmentação cultural, desse modo, coexistem em meio a permanentes atritos e confrontos.

A cultura-mundo desorganiza as consciências, os modos de vida e as existências. Em um clima de conquistas, de desconfianças e de descrença, novos desafios apresentam-se à educação e ao currículo, que precisam responder à incerteza presente no cenário. As procuras culturais fragmentam o social, e as indústrias 
do imaginário e do consumo parecem ameaçar os valores do espírito e a própria escola. A cultura se transforma em uma esfera cada vez mais politizada, conflituosa e mesmo trágica. Recorde-se que as agressões e as discriminações que marcam o mundo de hoje envolvem fortes motivações culturais, remetendo a intolerâncias e, consequentemente, a reivindicações identitárias.

Mas o que os autores denominam de regresso da cultura apresenta fortes possibilidades para o futuro, por serem imensas as possibilidades das ações humanas nesse terreno, sempre aberto às mudanças necessárias para "civilizar" a culturamundo. Se nossos autores realçam o valor do domínio político, podemos, também, acentuar as oportunidades que se abrem em decorrência de medidas tomadas, em diferentes níveis, na esfera educacional. A escola, o currículo e o professor certamente constituem objetos considerados nessas medidas.

Já ressaltei, em diversos estudos, a importância da cultura na formulação e no desenvolvimento de currículos. Tendo-a reiterado neste texto, passo a enfocar o conhecimento escolar, elemento nuclear do processo curricular. Recorro à recente argumentação de Michael Young (2009), renomado sociólogo inglês dedicado à discussão do currículo. Para ele, as escolas existem para ensinar conhecimentos que ofereçam ao estudante explicações confiáveis ou novas formas de compreender o mundo. 0 autor emprega ainda, no desenvolvimento de seus pontos de vista, a categoria diferenciação, com base na qual distingue o conhecimento escolar de outras modalidades não escolares de conhecimento. Sustenta que o enfraquecimento de fronteiras entre o conhecimento escolar e o conhecimento não escolar pode tornar o currículo menos relevante e dificultar o ensino do conhecimento poderoso, principalmente para o aluno em situação de desvantagem na sociedade.

Young tem criticado fortemente: a perspectiva que associa às escolas ao mercado e suas supostas demandas, a perspectiva tradicional que defende os grandes clássicos, além de rejeitar as contribuições do pós-modernismo e do pós-estruturalismo, que, a seu ver, relacionam todo e qualquer conhecimento a interesses.

Reconhecendo o caráter histórico do conhecimento, enfatiza que tal caráter não impede sua objetividade. Empregando a categoria diferenciação, posicionase a favor das fronteiras entre as disciplinas e entre o conhecimento científico e o conhecimento do cotidiano. Considera que as escolas existem primordialmente para ensinar o conhecimento que amplia os horizontes dos alunos e Ihes permite entender melhor o mundo. Distingue, então, o conhecimento poderoso - o saber teórico, especializado, independente do contexto e da escolha do aluno - do conhecimento do poderoso - relativo a quem adquire o conhecimento, a quem tem poder para fazê-lo. Insiste no valor das disciplinas escolares e de sua preservação no currículo. 
Certamente, os argumentos de Young devem ser criticados: cabe questionar sua análise do pós-modernismo e ao pós-estruturalismo, que ignora as contribuições dessas teorias para o pensamento pedagógico. Pode-se desconfiar do privilégio epistemológico concedido ao conhecimento poderoso, que negligencia a provável convergência entre o conhecimento poderoso e o conhecimento do poderoso. Por fim, há que se desafiar sua acirrada defesa das fronteiras entre diferentes tipos de conhecimento. Não serão desejáveis, para o avanço do conhecimento, rupturas entre as fronteiras disciplinares? Não será salutar uma tensão permanente entre a especialização disciplinar e a interdisciplinaridade, promovendo-se um permanente diálogo entre os docentes?

Sem pretender aprofundar nem a crítica a Young nem a defesa das teorizações pós, considero pertinente destacar dois pontos de vista. Primeiramente, vale ressaltar que as recentes teorizações de Young nos estimulam tanto a repensar questões referentes à seleção e à organização dos conhecimentos escolares, temáticas sempre presentes no pensamento curricular, quanto a fundamentar teoricamente os pressupostos que adotarmos a respeito da temática. Em segundo lugar, quero posicionar-me a favor da integração de distintas contribuições das perspectivas moderna e pós-moderna na análise de questões sociais e educacionais. Apoiar essa integração implica correr riscos, mas, com base em Alfredo VeigaNeto, considero ser possível nos desancorarmos de um dos dois mundos para nos situarmos no outro. Assim fazendo, faz sentido aceitar e incrementar a possibilidade do debate entre eles, que vejo como capaz de enriquecer as análises que se façam da escola e do currículo.

Considero que a discussão sobre o conhecimento escolar, bem como a integração de diferentes perspectivas na análise da escola e do currículo podem favorecer a promoção de nova postura em relação à escola, ao currículo e ao ensino, Essa postura precisa incluir a valorização da escola e de um trabalho cooperativo que envolva secretarias, gestores, docentes, discentes, membros da comunidade, membros de movimentos sociais. Trata-se de criar o que Apple (2002) denomina de unidade descentrada, na qual convivem múltiplos projetos progressistas, bem como múltiplas pedagogias críticas e pós-críticas articuladas em torno de lutas reais, em instituições reais, em comunidades reais.

\section{Concluindo}

Valorizei, neste texto, a importância da escola e de um empenho colaborativo com vistas à sua renovação. Defendi a centralidade do ensino, da cultura mais ampla e do conhecimento escolar nas discussões sobre currículo, debruçando-me sobre as argumentações de Michael Young em relação ao conhecimento poderoso e à diferenciação. Apresentei alguns questionamentos a esses pontos de vista, com a intenção de provocar reflexões e a procura de alternativas. 
$\mathrm{Na}$ defesa de um processo cooperativo na escola, acentuei a importância dos diálogos entre escola e secretaria e entre os diferentes sujeitos da escola. Talvez se faça conveniente estimular uma conversação complicada - expressão cunhada por William Pinar (2004) - entre os envolvidos no currículo e na gestão: uma conversação pautada pelo respeito, pela fundamentação e pelo esforço para construir um ambiente democrático e livre de ameaças na escola.

Em recente artigo, Alfredo Veiga-Neto (2012) nos convida a ocupar todos os espaços da casa em que habitamos e nos diz que é preciso ir aos porões. No porão encontram-se as raízes e a sustentação racional da casa. No sótão, encontram-se os sonhos, a fantasia, a imaginação e a inovação. É preciso escrutinar o porão ao máximo, já que ele guarda os arquétipos, que são construções contingentes, tomadas como verdades necessárias. Nossa tarefa é afastar a escuridão, desencantar os arquétipos, os preconceitos e os estereótipos. Racismos e homofobias, por exemplo, são práticas cujas raizes se encontram no porão. Nossa tarefa é levar para o sótão outros entendimentos, outras possibilidades e outros projetos, mais livres das amarras que nos restringem.

A análise é da esfera do porão, o agenciamento do sótão. 0 agenciamento mal fundamentado é mera militância. A análise fechada em si mesma é mera especulação. Nas decisões que se tomem na escola, cabe evitar a militância e exercer um ativismo produtivo, que nos faça avançar, pautados por um compromisso ético conosco e com os demais. Dai a importância de ir aos porões, para garantir um permanente cuidado teórico, metodológico e conceitual em relação a tudo que consideramos e fazemos em relação ao currículo e à gestão.

Há que se colocar sempre à prova a coerência, a pertinência e a realidade do que pensamos e dizemos. Daí a importância da crítica, para desentocar o pensamento e ensaiar a mudança, mostrando que as coisas não são tão evidentes quanto se acredita e que sempre podem ser transformadas. Dai ser preciso conhecer o que existe e o que se passa nos porões de nossos pensamentos e de nossas práticas educacionais e conhecer como se formaram historicamente as coisas que lá estão.

Compreensões mais refinadas do presente permitem que analisemos melhor experiências passadas e que nos abramos para possibilidades futuras, para alternativas, para a valorização e a renovação da escola e para a construção, em seu interior, de um clima sem ameaças. Para isso, há que se desconfiar sempre do pensamento e de suas supostas verdades, duvidando, criticando, experimentando e relendo o que parece inquestionável. Espero que este texto estimule a ida aos porões de nossos pensamentos e de nossas práticas referentes a ensino, currículo e gestão. Espero que este texto estimule também nosso deslocamento para o sótão, onde desenvolvemos a nossa capacidade de sonhar e de criar. Como nos diz José Eduardo Agualusa, "é nos sonhos que tudo começa". 


\section{Referências}

ALVES, N.; GARCIA, R. L. Para começo de conversa. In: ALVES, N.; GARCIA, R. L. (Org.) O sentido da escola. Rio de Janeiro: DPEA, 1999.

APPLE, Michael W. Currículo e poder. Educação \&t Realidade, Porto Alegre, v. 14, n. 2, p. 46-57, 1989.

Podem as pedagogias críticas sustar as políticas de direita? Cadernos de Pesquisa, Rio de Janeiro, n.116, p. 107-142, 2002.

Fly and the fly bottle: on Dwayne Hubner, the use of language, and the nature of the curriculum field. Curriculum Inquiry, [S. I.], v. 40, n. 1, p. 97-103, 2010.

BOURDIEU, Pierre. Contrafogos 2. Rio de Janeiro: Jorge Zahar, 2001.

BONDIOLI, Anna. Dos indicadores às condições do projeto educativo. In: BONDIOLI, Anna (Org.) 0 projeto pedagógico da creche e a sua avaliação. Campinas: Autores Associados, 2004.

CANÁRIO, Rui. A escola tem futuro?: das promessas às incertezas. Porto Alegre: Artmed, 2006.

CANDAU, Vera Maria. Construir ecossistemas educativos - reinventar a escola. In: CANDAU, Vera Maria (Org.). Reiventar a escola. Petrópolis: Vozes, 2000a.

A didática hoje: uma agenda de trabalho. In: CANDAU, VERA MARIA (Org.) Didática, currículo e saberes escolares. Rio de Janeiro: DPCA, $2000 \mathrm{~b}$.

FAIRCLOUGH, Norman. Language and globalization. London: Routledge, 2008.

FREITAS, Luiz Carlos. Eliminação adiada: o caso das classes populares no interior da escola e a ocultação da (má) qualidade do ensino. Educação \&t Sociedade, São Paulo, v. 28, n. 100, p. 965-987, 2007.

HALL, Stuart. A centralidade da cultura: notas sobre as revoluções de nosso tempo. Educação \&t Realidade, Porto Alegre, v. 22, n. 2, p. 15-46, 1997.

LIPOVETSKY, Gilles; SERROY, Jean. A cultura-mundo: resposta a uma sociedade desorientada. Lisboa: Edições 70, 2010.

MOITA LOPES, Luiz Paulo. Identidades fragmentadas. Campinas: Mercado de Letras, 2002. 
MOREIRA, Antonio Flavio B. Os princípios norteadores de políticas e decisões curriculares. Revista Brasileira de Política e Administração da Educação, Recife, v. 28, n. 1, p. 180-194, out. 2012.

MOREIRA, Antonio Flavio B.; KRAMER, Sonia. Contemporaneidade, educação e tecnologia. Educação \&t Sociedade, São Paulo, v. 28, n. 100, p. 1037- 1057, mar. 2007.

PINAR, William F. What is curriculum theory? Mahwah, New Jersey: Lawrence Erlbaum, 2004.

SAHLBERG, Pasi. Finish lessons: what can the world learn from educational change in Finland?. New York: Teachers College Press, 2011.

SILVA, Tomaz Tadeu. Identidades terminais: as transformações na política da pedagogia e na pedagogia da política. Petrópolis: Vozes, 1996.

. O currículo como fetiche. Belo Horizonte: Autêntica, 1999.

SOUSA SANTOS, Boaventura. Os processos da globalização. IN: SOUSA SANTOS, Boaventura (Org.). A globalização e as ciências sociais. São Paulo: Cortez, 2002.

VEIGA-NETO, Alfredo. É preciso ir aos porões. Revista Brasileira de Educação, rio de Janeiro, v. 17, n. 50, p. 267-282, 1012.

WILLIAMS, Raymond. Marxism and literature. Oxford: Oxford University Press, 1985.

YOUNG, Michael. Para que servem as escolas? In: PEREIRA, Maria Zuleide, C.; CARVALHO, Maria Eulina P.; PORTO, Rita de Cassia C. (Org.). Globalização, interculturalidade e currículo na cena escolar. Campinas: Alínea, 2009.

Recebido em: 09/06/2013

Aceito para publicação em: 05/08/2013

\section{Curriculum and management: proposing a partnership Abstract}

Many schools are not succeeding in teaching the students what can be necessary in an uncertain future. To be able to offer knowledge, abilities and values that can be needed to live in our contemporary world, school has to be rethought and renewed. The success of the Finish experience in education can be helpful to 
stimulate us to dream with quality at school, to make all the efforts to construct it, to treat critically external advice, to respect and value the teacher and to develop an atmosphere free of competition and control at schools and classrooms. To create this quality, the curriculum is a central element. It is necessary to discuss it, taking into account culture and school knowledge. In this process, cooperation at schools is indispensable, and it should involve dialogues between school and education secretary and among the different professionals that work at school. Keywords: School. Curriculum. Management. Culture. School knowledge.

\section{Currículo y gestión: propuesta de acción conjunta Resumen:}

En muchas escuelas se deja de enseñar a los alumnos lo que se puede convertir en saber necesario, en un futuro lleno de incertidumbres. Para que se les pueda ofrecer conocimientos, habilidades y valores indispensables para vivir en nuestros días, hay que reflexionar sobre la escuela y renovarla. La exitosa experiencia finlandesa en educación nos puede ser útil, incentivándonos a anhelar una escuela de calidad, esforzarnos por hacerla realidad, a tratar críticamente las experiencias de otros países, respetar al profesor y valorarlo, además de crear un ambiente libre de amenazas en las escuelas y en el aula. En tal negociación de la calidad, el currículo puede ser el elemento central. Hay que discutirlo, considerando, fundamentalmente, la cultura en que se inserta y el conocimiento escolar. En dicho proceso es necesario la cooperación en la escuela, construyendo oportunidades de diálogo con las secretarias de educación, así como entre los distintos profesionales que actúan en la institución escolar.

Palabras clave: Escuela. Curriculo. Gestión. Cultura. Conocimiento escolar. 